\title{
Scale on Attitude of Stakeholders towards Agricultural Innovation System
}

\author{
P. H. Vihariya" and R. D. Pandya \\ Department of Extension Education, N. M. College of Agriculture, NAU, \\ Navsari, 396450, Gujarat, India \\ *Corresponding author
}

\section{A B S T R A C T}

\begin{tabular}{|l|}
\hline K e y w o r d s \\
Attitude, \\
Agricultural \\
Innovation System, \\
Scale, Stakeholder, \\
Innovation
\end{tabular}

Generating and applying new knowledge is important for all enterprises, including farming. New knowledge enhances the productivity, competitiveness, and sustainability in farming, but it is not widely adopted. In this situation one has to search new ways and means. Limitations of NARS and AKIS have provided the reasons for Agricultural Innovation System (AIS) in India. AIS help to understand how the process of agricultural innovation takes place and how it's relevance and quality can be enhanced. Hence to understand the feelings of involved stakeholders, a scale was developed to measure the attitude of stakeholders towards agricultural innovation system. A Likert's scaling technique (1932) was found appropriate due to large numbers of items. A schedule of statements was sent to 80 judges to found appropriateness by assigning the score on each item. Based on the ' $t$ ' value, 25 items were finally selected to constitute the scale to measure attitude of stakeholders towards AIS. Reliability of the scale found to be 0.8914 .

\section{Introduction}

Change is the core of development. The world is changing fast and so are its needs. With the change in context of agricultural development, the approaches to innovation have also been changed. National Agricultural Research System (NARS) was the open up a way, but Agriculture Knowledge and Information System (AKIS) come up to alleviate rapid changes over the years. The present agricultural research efforts are failing to bring about the social and economic transformations due to one or the other reasons. One cannot solve the challenges of tomorrow resolved by yesterday's methods.
To cope, compete and survive in emerging challenges, it becomes necessary to develop new approaches. In this context, the concept of Agricultural Innovation System (AIS) approach offers a new framework for analysing the role of science and technology and their interaction with other actors to generate goods and services. It recognizes the importance of certain types of relationships and linkages for information flow in everchanging biophysical and social environments. If sustainable innovations are targeted, the key challenges faced by agricultural sector are food security and climate change aspects should be promoted. Several literatures reported that the attitude of 
an individual plays a significant role in the adoption or rejection of an innovation. In this regards, an attempt was carried out to construct a scale to measure the attitude of stakeholders towards Agricultural Innovation System.

\section{Materials and Methods}

Thurstone (1946) define an attitude as the degree of positive or negative affect associated with some psychological object. Among the available techniques for constructing a scale, the Likert's scaling technique (1932) was found appropriate due to large numbers of items. The steps followed in construction of scale to measure the attitude of stakeholders towards AIS are discussed below.

\section{Selection of indicators}

The available literature was reviewed and from them 12 indicators related to AIS was resorted. A list of indicators was circulated among the 30 extensionist and their opinions were obtained on 10 point continuum to know its appropriateness for the study. The indicator wise frequencies were converted in master sheet. For each indicator weighted mean and standard error were calculated. The obtained values were arranged in ascending order. Out of 12 indicators, those having less than 70 per cent value were omitted. This way 10 indicators were finalized for the study.

\section{Item Collection}

The items making up an attitude scale are known as statements. A statement may be defined as anything that is said about a psychological object (Edwards, A. L. 1957). Initially, 110 items were made according to selected indicators from the relevant literatures and converted them in context to present requirement. The statements, thus selected, were edited on basis of the criteria suggested by Edward and Kilpatrick (1948) to eliminate the ambiguity.

\section{Item analysis}

The three continuum criterion was used to judge each statement on the degree of most appropriate to not appropriate. A schedule was prepared with 100items was sent online through 'Google forms' as well as through personal contact for judging the relevancy to the personnel working as extension educationist, sociologist and psychologist were identified from various universities of India. It was also sent through post to retired eminent personalities of our fraternity judges the relevancy of items. Out of the 135, 95 judges had responded. The investigator has found that some of the judges have responded very carelessly, misunderstand the directions and not be aware about the concept under present study hence, 15 schedules were eliminated. Lastly, 80 schedules were kept for the construction of scale.

\section{Selection of item}

A three point rating method was followed as; 1 for not appropriate, 2 for appropriate and 3 for most appropriate. The responses of 80 judges on 100 items were transferred into the master sheet. As basis for rejecting of statements, the method of summated ratings was used for item analysis. Then considered the frequency distribution of scores based upon the responses to all statements.

The 25 per cent of them with highest total scores (20 items) and 25 per cent lowest total scores (20 items) were considered. These two groups provide criterion groups in terms of which to evaluate the individual statements. The paired ' $t$ ' test was applied to measure the extent to which a given statement differentiates between the high and low groups. 
According to summated ratings method, a set of 25 statements was desired that were differentiating between the high and low groups. After computing of ' $t$ ' value for all the items the statements having ' $t$ ' value equal to or greater than 2.02 were selected is given in table 1. The first 25 statements with the largest value of ' $t$ ' were selected for construction of attitude scale.

Based on the ' $t$ ' value, 25 statements numbering $71,42,58,28,81,88,67,60,96$, $91,37,35,73,68,48,54,77,31,98,56,07$, $61,78,95$ and 33 of schedule were finally selected to measure the attitude of the stakeholders towards agricultural innovation system.

Table.1 Selected attitude statements for present study

\begin{tabular}{|c|c|c|}
\hline Sr. & Statements & 't' value \\
\hline 1 & AIS makes stakeholders more competent for generating new knowledge. $(+)$ & 6.24 \\
\hline 2 & AIS initiates the concept of demand driven research. $(+)$ & 4.17 \\
\hline 3 & AIS fosters the interaction of actors involved in innovation. $(+)$ & 4.00 \\
\hline 4 & Collaboration creates hindrance to get consensus in goal. (-) & 3.90 \\
\hline 5 & AIS develops new avenues of market for farming community. $(+)$ & 3.73 \\
\hline 6 & Linking activities improves the effectiveness of AIS. $(+)$ & 3.67 \\
\hline 7 & AIS initiates collaborative efforts in decision making for organization. $(+)$ & 3.52 \\
\hline 8 & AIS have introduced as economically viable approach. (+) & 3.44 \\
\hline 9 & AIS strengthens the stakeholders' networks. $(+)$ & 3.35 \\
\hline 10 & Individual weakness may come out through interactive learning in AIS. (-) & 3.32 \\
\hline 11 & AIS works with applied knowledge. (+) & 3.25 \\
\hline 12 & AIS emphasizes on how the capacity of stakeholders can be scaled up. $(+)$ & 3.16 \\
\hline 13 & Capacity development is the key for fostering agricultural innovation. $(+)$ & 3.13 \\
\hline 14 & Collaboration efforts can bring the change in agricultural sector. $(+)$ & 3.11 \\
\hline 15 & $\begin{array}{l}\text { AIS strengthens is the capacities of stakeholders to deal with agricultural } \\
\text { challenges. }(+)\end{array}$ & 3.09 \\
\hline 16 & Collaborated stakeholders can share their resources with other. $(+)$ & 3.05 \\
\hline 17 & AIS strengthens the skills of stakeholders to enable innovation. $(+)$ & 3.02 \\
\hline 18 & Collaboration is a time-consuming process for getting right people. (-) & 2.97 \\
\hline 19 & AIS is road map for effectively work together for doubling farm income. $(+)$ & 2.92 \\
\hline 20 & AIS helps to stakeholders for doing the right things at right time. $(+)$ & 2.85 \\
\hline 21 & Misunderstanding occurs among stakeholders due to collaboration. (-) & 2.79 \\
\hline 22 & Strengthen of AIS depends on innovative capabilities of stakeholders. $(+)$ & 2.75 \\
\hline 23 & Making strong linkage in AIS is futile exercise. (-) & 2.73 \\
\hline 24 & AIS plays an important role to enhance the economic status of farmers. $(+)$ & 2.70 \\
\hline 25 & $\begin{array}{l}\text { A linkage among stakeholders is the present demand for agricultural } \\
\text { development. }(+)\end{array}$ & 2.64 \\
\hline
\end{tabular}

\section{Reliability of the scale}

Reliability is defined as the probability that a product, system, or service will perform its intended function adequately for a specified period of time, or will operate in a defined 
environment without failure. The constructed scale on attitude for measurement was tested for its reliability by using the split half method. It was introduced to 20 respondents of non-sample area. The coefficient of reliability between these two sets of score was calculated by Rulon's formula. The coefficient of reliability between two sets of score was found to be 0.8914 which was significant at 1 percent level.

\section{Validity of the scale}

The content validity of the scale was tested. It is the delegate or sampling ampleness of the substance, the content, the issue and the subjects of an estimating instrument. This technique was utilized in the current scale for decide the content validity of the scale. As the substance of the disposition was overall secured the topic under the examination through literature and expert opinion, it was expected that current scale fulfilled the content validity.

\section{Administering the scale}

The selected 25 statements for the final format of the attitude scale were randomly arranged to avoid the biases, which might contribute to low reliability and detraction from validity of the scale. Out of them, 5 statements were showing unfavourable attitude and 20 statements were of favourable attitude. Likert (1932) suggested five points' continuums to get responses from respondents. They were strongly agree, agree, undecided, disagree and strongly disagree with respective weights of $5,4,3,2$, and 1 for the favourable statements and with the respective weights of $1,2,3$, 4and 5 for the unfavourable statements.

\section{Application of research}

It is applicable to measure the attitude of stakeholders towards agricultural innovation system. It helps to understand the positive or negative feeling of stakeholders towards agricultural innovation system.

Research Category: Agricultural Extension, Innovation system

\section{References}

Likert, R. (1932) A technique for the measurement of attitudes. Arch. Psychol., No.140.

Thurstone, L. L. (1946) Comment. Amer. J. Sociol., 39-50.

Edwards, A. L. (1957) Techniques of attitude Scale Construction., 10., 149-155.

Edward, A. L. and Kilpatrick, F. P. (1948). A technique for construction of attitude scales. Journal of Applied Psychology, 32: 374- 384.

Guilford J.P. (1954) Psychometric Methods. Tata McGraw Hill Publishing Co., Bombay, 597.

\section{How to cite this article:}

Vihariya, P. H. and Pandya, R. D. 2020. Scale on Attitude of Stakeholders towards Agricultural Innovation System. Int.J.Curr.Microbiol.App.Sci. 9(09): 1497-1500.

doi: https://doi.org/10.20546/ijcmas.2020.909.189 